\title{
Pedagogical Innovations in Language Teaching Methodologies
}

\author{
Minoo Alemi \\ Sharif University of Technology, Tehran, Iran \\ Email: alemi@sharif.ir \\ Parisa Daftarifard \\ Islamic Azad University (Research \& Science Branch), Tehran, Iran \\ Email: pdaftarifard@yahoo.com
}

\begin{abstract}
Language teachers have always been concerned about the inadequacy of conventional methods of language teaching in education systems. As a result, the language teaching pendulum is swinging from methods to post-method pedagogy, although it still remains in motion. The dual focus on both socio-cultural theories to second language acquisition (SLA) and improvements in technologies wins the attention of practitioners, curriculum designers, and students as the major stakeholders in applied linguistics. This has resulted in greater emphasis on the important role of techniques and technologies in language teaching. Many have tried to find a more innovative direction in this respect (Rodgers, 2000). This article, along with reviewing different predictions made in this direction, takes a more edu-sociocultural-technological perspective to address the potentially important issues in language teaching in future.
\end{abstract}

Index Terms - language teaching, SLA, sociocultural theories

\section{INTRODUCTION}

Past language teaching is associated with the "Age of Methods" (Rogers, 2000, p.1). The language teaching pendulum has swung away from grammar translation to the direct method, and then to alternative methods (Richards \& Rogers, 2003). Such shifts from one method to another only "provide ample inferential evidence of [consecutive] lack of success" (Sheen, 1994, p. 127). The result of such frustration was the shift from teacher to learner (Freeman \& Richards, 1993), from outside feeding theories to inside ones (Richards, 1996), from method-based top-down to teacher-based bottom-up approaches (Richards \& Rodgers, 1987; Freeman \& Richards, 1993).

Frustrated by lack of success through such shifts from one method to another, scholars faced "scatter-fire approaches to language teaching" (Rogers, 2000). The anti-method movement from beyond methods (Richards, 1990) to teachers' sense of plausibility (Prabhu, 1990) and finally to post method era (Kumaravadivelu, 1994) is indicative of a shift in view from curriculum developer towards teacher and from teacher towards learner; teaching English is inclined to be fed from internal sources (internalization) instead of external sources (externalization). Internalization manifested in focusing more on learners' strategic ways of learning: teacher-learner mismatches in terms of cognitive, metacognitive and affective factors; as well as moderating self-initiation in heuristic learning. In this respect, Schunk (2000) proposed six factors based on which learning issues are discussed and evaluated. These factors are about (1) the way leaning occurs, (2) factors affecting learning, (3) the role of memory, (4) the role of motivation, (5) the role and mechanism of transfer, and (6) the nature of learning anticipated by the theory . Based on these six points, he classified learning theories into three major epistemologically different paradigms of behavioral, cognitive, and constructive psychology and theories.

\section{A. Present (Post Method Era)}

Kumaravadivelu (2001) proposes the concept of postmethod pedagogy, saying that the concept rests on three parameters, namely on particularity, practicality, and possibility. Particularity refers to the belief that any language teaching program "must be sensitive to a particular group of teachers teaching a particular group of learners pursuing a particular set of goals within a particular institutional context embedded in a particular sociocultural milieu" (p. 538). This localized perspective cannot be assigned to a universally presumed concept of method. Practicality refers to the interrelationship of theory and practice. One misperception is that the West should theorize and the East should consume. The practicality issue believes in "marginalize[d] local knowledge" and that theory of practice should be generated by the practitioners. The third parameter is the parameter of possibility. Kumaravadivelu (2001), based on Freire and Giroux's concepts of critical pedagogy, states that "pedagogy, any pedagogy, is implicated in relations of power and dominance, and is implemented to create and sustain social inequalities" (p. 542). Kumaravadivelu believes that teachers should be empowered to help learners critically reflect on the social and historical conditions that have shaped their cultural lives. 
According to Kumaravadivelu (2003), postmethod pedagogy is a reaction to "method as a means of marginality" (p. 454 ) in the sense that pedagogy should take a bottom-up process to give the teachers power to build their own practices in the classroom based on the plausibility they develop through their personal experience, educational background and consultation with colleagues (Kumaravadivelu, 1994).

Kumaravadivelu (1994) develops the concept of principled pragmatism which is based on pedagogy in which "the relationship between theory and practice, ideas and their actualization can only be realized within the domain of application...through the immediate activity of teaching" (p. 31). Elsewhere, Kumaravadivelu (2006) depicts a three dimensional framework of language pedagogy which entails the intralingual-crosslingual dimension, the analyticexperiential dimension, and the explicit-implicit dimension. These dimensions are not dichotomized but form a continuum along which one moves from intralingual, analytic, or explicit at one end to crosslingual, experiential, and implicit at the other end. The intralingual end suggests that only L2 should be used in the classroom, no translation be allowed, and the people who learn a second language develop a kind of co-ordinate bilingualism (they develop two systems). In contrast, the crosslingual approach suggests that L1 can be used as a reference system in class that cultures and languages have some similarities, and learners who learn another language develop a compound bilingualism (single system).

Approaches at the analytic end of the continuum focus on code, on language as a medium; they incorporate observation and usage of decontextualized language, and responses are predictable and emphasize on accuracy. In contrast, the approaches from the experiential end focus on communication, are message centered, and emphasize participation and language use. They focus on contextualized language, information gaps, and fluency, and priorize interpersonal interaction. The explicit end focuses on rationality, formality, intellectual strategies, conscious learning, cognitivism and inferencing, and systematic study. In contract, the implicit end emphasizes the intuitive aspect of learning, subconscious acquisition, and incidental and global understanding; it is mostly behaviorist in the sense that it is empiricist.

\section{B. Macro Strategies}

As an alternative to method, Kumaravadivelu (1994) proposes a strategic framework for second language teaching which depicts many important findings of second language acquisition research, such as output hypothesis, input hypothesis, autonomy, and strategy training. He posits 10 macro strategies for language teaching:

1. Increasing Learning Opportunities: Teachers should create learning opportunities and make necessary changes.

2. Reducing Perceptual Mismatches: Teachers should minimize mismatches such as cognitive, linguistic, cultural, and instructional aspects between teachers' intentions and learners' interpretations.

3. Helping Negotiated Interaction: Teachers should encourage students to participate in meaningful interaction.

4. Encouraging Learner Autonomy: Teachers should help learners to learn how to learn and promote self-directing.

5. Increasing Language Awareness: Teachers should design activities that foster language awareness.

6. Activating Self Discovery: Teachers should provide rich textual data so that learners can infer underlying rules

7. Contextualizing Linguistic Input: Teachers should present linguistic input within thematic contexts reflects the natural use of language.

8. Integrating Language Skills: Language skills such as listening, speaking, reading and writing should be integrated.

9. Ensuring Social Relevance: Teachers should be sensitive to the societal, political, economic, and educational environment in L2.

10. Raising Cultural Consciousness: Learners should be encouraged to engage in a process of classroom participation that acknowledges their power and knowledge.

\section{Future}

With the emergence of sociocultural theories regarding learning in general and concerning language learning in particular, the realm of applied linguistics is finding a new direction. More dynamic view towards the nature of language turned scholars from static view to competence towards more interactive and dynamic view towards explicating what the nature of language is (Young, forthcoming). Moreover, the integration of technologies into language learning and teaching contexts is indicative of coral attention to the facilitative role of technology at the service of dynamicity of competence; Games, E-pet scoring, E-portfolio, Self initiating and many other activities are among those that might dominate language classroom instruction.

\section{My Language is $M E$}

Richards (2002) discussed the components of communicative curriculum as (1) language arts; (2) language for a purpose; (3) My language is ME: Personal English language use; (4) You be...I'll Be....Theater arts; and (5) beyond the classroom. By language arts he meant whatever a teacher does (translation, syntax, morphology, and phonology) to draw learners' attention to form. Language for a purpose refers to the variety of needs for which learners start learning English. Not all learners learn English for the same purpose. Richards states, "purposeful language is a built-in feature of the learning environment" (p. 4). My language is ME refers to the personal English language use and refers to learners' identity. You Be, ...I'll Be....: Theater arts refer to famous saying from Shakespeare that all the world is a stage. Teachers are coaches who provide support, strategies, and encouragement for learners as they explore new ways 
of being. Beyond the classroom is the final component of a communicative curriculum. It refers to the fact that learners should be prepared for language use in the real world. Language identity, using language for personal purposes and being flexible in adopting different roles in the classroom are among those things that might be in the focus of attention in language education.

\section{E. Rogers's (2000) Predictions}

Rodgers (2000) tried to predict the future of language learning and instruction. As he describes, he used the "yesterday's method labels" idiosyncratically to conceptualize future. He listed future of methodology and language teaching in ten statements:

1. Teacher/Learner Collaboration: Using matchmaking techniques to link learners and teachers who have similar styles and approaches to language learning.

2. Method Synergistics: Crossbreeding elements of various methods to find those practices which best support effective learning.

3. Curriculum Developmentalism: Viewing methodology as a component integrated in a larger view of instructional design.

4. Content-Basics: Assuming that language learning is a by-product of a focus on meaning, on acquiring some specific topical content.

5. Multi-intelligencia: Basing instruction on a "multiple-intelligences" view, in which different approaches play to different learner talents.

6. Total Functional Response: Reconstructing the Notional/Functional idea with some new systemic twists.

7. Strategopedia: Teaching learners the strategies they need so that they can learn on their own.

8. Lexical Phraseology: Recrafting both the nature and substance of language learning (LL) to focus on lexical phrases and collocations.

9. O-zone Whole Language: Engaging all aspects of language study-literature, language history, and linguistic analysis - in support of second language learning

10. Full-frontal Communicativity: Engaging all aspects of human communicative capacities —expression, gesture, tone, and so forth - in support of second language learning

Rogers tried to reconceptualize what has been dominating the past to predict the future. By teacher learner collaboration he referred to the importance of learner's and teacher's style and strategy in the sense that any mismatch between learners' strategies and styles and the method used in the classroom would be doomed to failure. By method synergistic, he first referred to the failure of method as a general concept. Rodgers believed that there are some commonalities among methods but they are too abstract to be noticed. He referred to such communalities as supraordinate communalities. He makes a distinction between classroom internal and classroom external. He believed that classroom internals such as teachers' belief should be supported. Curriculum developmentalism is a new term he invented. He believed that educational design consisted of four aspects of knowledge (input and output as well as content and topic), instructional (methods, materials, programs, technologies, and educational environments, time, scheduling), learner (ages, proficiency, and developmental stages), and administrative (choice of instructional model). He stated that CLT has undergone three periods, namely Wilkins's functional/notional, Munby's period of needs analysis, and Prabhu's period of techniques. He believes that the future will be an integration of these periods.

Content basics means that language learning is a by-product of a focus on form. Multi-intelligence refers to raising the teacher's awareness of learner diversity and interest. By total functional response he meant considering genre, language functions, and text types. Strategopedia means enabling learners to initiate, control, and maintain their own learning through learning strategies. Lexical phraseology holds the idea that only a minority of spoken clauses is novel and this implies chunking issues. By chunk, we mean that certain word collocation is learned through an exemplar system (N. Ellis, 2003). O-Zone whole language refers to the idea that language incorporates literary study, authentic content and learner collaboration in language teaching. In this respect, learners, through comparing the parallel text, can focus on form through consciousness-raising tasks. Finally, full frontal communicativity means that communication involves many features of speech, including attitude, meaning, information, and every aspect of conveying the message to the listener and reader.

\section{PROCEDURE}

\section{A. Gossiping as a Teaching Activity}

Baw (2002) used gossiping as a way of making shy students talk in English in the classroom. He wished to give extended oral practice to students who remain rather inhibited, in spite of having a working knowledge of grammar. In other words, it is an attempt to encourage less fluent students to talk with inspiration. There are three types of involvement in conversation: (1) self-involvement of the speaker, (2) interpersonal involvement, and (3) being involved in what is being talked about. He believed that gossip is the most frequent type of communication and found that few people resist doing it. The purpose of gossiping in education is to help learners become fluent in speaking. He used the teacher as the model for being the object of gossip or a character from a story. For the first model, the students were given a note to trigger their talk or gossip in English. 
For the next exercise the students get the opportunity to invent their own gossip and go through three stages to practice. The first one is a brief discussion about the plot. The second stage is to express their contempt for the main character of the story and the third stage is to prepare for giving an oral presentation.

\section{B. Game Play either Through CALL or Face to Face Teaching Practice}

Ting (2009) underlines the fact that the purpose of communicative language teaching is to prepare students for the real world activity, saying that the learners should be able to express language functions (such as requesting, congratulating, apologizing, complaining, consoling, and promising) appropriately. He offers the game of Sudoku, a kind of number puzzle, as an ideal authentic context for practicing language functions.

\section{Using E-pet as Scoring E-portfolio}

Tuksinarajarn and Todd (2009) used E-portfolios instead of paper-based portfolios. The E-portfolio has several advantages: they are easy to search, enable the use of multimedia projects, and allow efficient feedback on student work. It includes the following features:

An attractive, user-friendly webpage ...

A learner contract between the student and teacher that outlines a practical and concrete study plan for the completion of certain goals and activities within a set time. Involving students in decisions about assignments makes their learning more relevant.

A personal profile page resembling social networking sites, such as MySpace and Facebook that students customize with pictures and other information.

A mechanism to give students external rewards (in addition to grades) for learning new vocabulary items, grammar points, and learning strategies,

A link that lists the best student portfolios. This will motivate the model students by publicly acknowledging their achievements, and their classmates will view the model portfolios and learn from that work. (p. 23).

Teachers can use E-pet as the scoring system for children. The students are given animated eggs and can name these. These eggs will grow into pets. With the submission of quality work these pets grow and gain power so that finally they can fly.

\section{More ESP and Workplace Integration}

Bouzidi (2009), as well as Reilly (2001), emphasize the importance of a workplace needs analysis to be incorporated into the preparation of a syllabus. Bouzidi focuses on the hospitality industry. Through three steps, he prepares the material. The first step is the survey of employers and employees through interviews. The second step is to evaluate the ESP textbooks. In doing this, several questions should be answered, including "(1) does the textbook cover the language functions the learners are likely to use in their future; (2) does the textbook cover the topics/situations learners are likely to encounter in their future professional environment; (3) does the textbook emphasize the linguistic skills needed; (4) does the textbook content adequately reflect local and target language cultures; and (5) does the textbook take into account local teaching/learning style?" (pp. 13-15). These questions highlight the importance of considering the language functions, topics, linguistic skills, and cultural features for the language course. These considerations are localized and should be considered dialogically. Perhaps, in the future, more textbooks will integrate local situations (like workplace) in a multi-voiced framework. By multi-voiced, I mean all aspects of language and culture should be localized. The third step is supplementing the ESP textbook.

\section{CONCLUSION}

Based on what the researchers mentioned above, they predict the following innovations in the short- or long-term future. First, besides taking a proficiency test, students may take a matching test to be grouped with the most similar teacher and groups in terms of style and strategy. Mismatches discussed in Kumaravadivelu's article have been widely neglected although they have an important impact in developing multi-voiced competencies in learners. Second, language learning, to many post-Vygotskyan scholars, is dialogic instead of dialectic. The new concepts of practicum, collaborative dialogue for output (Swain, 2000), affordance for input (Van Leir, 2000) and dynamic competence (Johnson, 2004) all indicate of such shifts in view. Third, before each language course, students might be required to be educated in self-initiation and problem posing strategies in order to create an idiosyncratic voice for self. Fourth, referring to emancipatory competence, the researchers believe that a more glocolized communicative competence which accounts for the dynamic nature of language is needed to be defined. Emancipatory competence enables the speakers to legitimize their competence in a way that allows them to adjust their pragmatic knowledge to the context they encounter. This means that a native speaker might lack this competency. Fifth, Tully (2009) explains the mind mirror project, which develops language skills through critical thinking. I believe that, in the future, critical thinking will play an important role in the English language classroom and this can be done through mind mirror projects and texts. Sixth, critical thinking has six characteristics: interpretation, analysis, evaluation, interference, explanation and self-regulation among which three features are the most important. Interpretation consists of two skills, namely, of categorization and clarifying meaning. Categorization happens when students locate appropriate elements in the story, and clarifying 
meaning refers to connecting these elements together. Inferencing refers to drawing a conclusion through finding relevant information and determining the consequences in terms of data beliefs and other evidence. Self-regulation refers to learners monitoring and evaluating their work trough questioning, confirming, or correcting. Seventh, the mind mirror project provides students with great opportunity to demonstrate critical thinking skills. It increases students' selfawareness and autonomy. In the mind mirror project, learners prepare two quotations, two original statements, two images and two symbols for every story they read. This way, they work on a text once individually and once in a group through reading the teachers' interpretations. Eighth, textbooks might in the future be mainly corpora based books through which learners become familiar with the authentic use of vocabulary and grammar. As Salsbury and Crummer (2008) state Corpus is a body of written and spoken language that teachers and researchers collect and analyze. Teachers compiled corpus from textbooks as well as from representative journal articles and manuals that students use in their university content courses. The students analyze the corpus to reinforce lessons with grammar, vocabulary and writing. The students identify patterns in language use that different from how they intuitively use the foreign language and even from how the language is presented and taught in their text books. (p. 28)

Ninth, Richards (2002) talk about my language is ME as one of the component of communicative language teaching. In the future, language as voice will likely be more highlighted. The concepts Englishes instead of English, both in testing and teaching, will be more highlighted. Tenth, language identity, using language for personal purposes and being flexible in adopting different roles in the classroom are among those objectives that might be the focus of attention in the language education. Eleventh, language books might look like game-based textbooks through which all micro and macro skills could be practiced. Twelfth, the E-Pet idea is a very interesting way of scoring. To us, it seems to be based on the sociocultural aspect of language learning and, this way, learners are involved in learning through selfresponsibility. Thirteenth, more multi-voiced perspective is taken into account when doing needs analysis. This includes both localized features and globalized features of target language. Finally, as Rogers (2000) explicated and predicated, and as Farjami (2001) researched, misconception is an important component of language teaching which if not considered might lead to a detrimental and unexpected result. Kumaravadivelu $(1994,2006)$ explicates the concept in detail. What we predict is that, at the beginning of the term, a test measuring conceptions or misconceptions will be given to students. Students will be grouped in terms of the strategies and styles they use and they would be matched in this respect with their teacher and course books. Moreover, it is possible that the future classroom will be a workplace to focus on ameliorating the learners' different types of misconceptions.

\section{REFERENCES}

[1] Baw, S. Schwa (2002). Transforming the whole class into gossiping group. English Teaching Forum Online, 40(2). http://exchanges.state.gov/englishteaching/forum/archives.html (accessed 13/01/2010).

[2] Bourke, J. M. (2008). A rough guide to language awareness. English Teaching Forum Online, 46(1). http://exchanges.state.gov/englishteaching/forum/archives.html (accessed 13/01/2010).

[3] Bouzidi, H. (2009). Between the ESP classroom and the workplace: Bridging the gap. English Teaching Forum Online, 48(2). http://exchanges.state.gov/englishteaching/forum/archives.html (accessed 13/01/2010).

[4] Ellis, N. C. (2003). Construction, chunking, and connectionism: The emergence of second language structure. In C. Doughty \& M. H. Long (Eds.), The handbook of second language acquisition (pp. 63-103). New York: Blackwell.

[5] Farjami, H. (2001). Misconception analysis: A necessary complement to foreign language teaching. English Teaching Forum Online, 39(2). http://exchanges.state.gov/englishteaching/forum/archives.html (accessed 13/01/2010).

[6] Freeman, D., \& Richards, J. C. (1993). Conceptions of teaching and the education of second language teachers. TESOL Quarterly, 27(2), 193-216.

[7] Kumaravadivelu, B. (1994). The postmethod condition: Emerging strategies for second/foreign language teaching. TESOL Quarterly, 28(1), 27-48.

[8] Kumaravadivelu, B. (2001). Toward a postmethod pedagogy. TESOL Quarterly, 35(4), 537-560.

[9] Kumaravadivelu, B. (2003). A postmethod perspective on English language teaching, World Englishes, 22(4), 539-550.

[10] Kumaravadivelu, B. (2006). Understanding language teaching: From method to postmethod. New Jersey: Lawrence Erlbaum Associates, Publishers.

[11] Johnson, J. (2004). A philosophy of second language acquisition. New Haven: Yale University Press.

[12] Prabhu, N. S. (1990). There is no best method-why? TESOL Quarterly, 24(2), 161-176.

[13] Reilly, P. (2001). Meeting learners' academic needs. English Teaching Forum Online, 39(2). http://exchanges.state.gov/englishteaching/forum/archives.html (accessed 13/01/2010).

[14] Richards, J. C. (1990). The language teaching matrix. Cambridge: CUP.

[15] Richards, J. C. (1996). Teachers' maxims in language teaching. TESOL Quarterly, 30(2), 281-296.

[16] Richards, J. C. (2008). Growing up with TESOL. English Teaching Forum Online, 47(2). http://exchanges.state.gov/englishteaching/forum/archives.html (accessed 13/01/2010).

[17] Richards, J. C., \& Renandya. W. A. (eds). (2002). Methodology in language teaching an antology of current practice. Cambridge: Cambridge University Press

[18] Richards, J. C., \& Rodgers, Th. S. (1987). Through the looking glass: Trends and directions in language teaching. RELC, 18, 45-73.

[19] Richards, J. C., \& Rodgers, Th., S. (2003). Approaches and methods in language teaching ( $2^{\text {nd }}$ ed.). Cambridge: CUP.

[20] Rogers, T. (2000). Methodology in the new millennium. English Teaching Forum Online, 28(2). http://exchanges.state.gov/englishteaching/forum/archives.html (accessed 13/01/2010). 
[21] Savignon, S. J. (2002). Communicative curriculum design for the $21^{\text {st }}$ century. English Teaching Forum Online, 40(1). http://exchanges.state.gov/englishteaching/forum/archives.html (accessed 13/10/2010).

[22] Schunk, D. H. (2000). Learning theories: An Educational perspective. NY: Prentice Hall Publishers.

[23] Sheen, R. (1994). A critical analysis of the advocacy of the task-based syllabus. TESOL Quarterly, 28(1), 127-153.

[24] Salsbury, T., \& Crummer, C. (2008). Using teacher-developed corpora in the CBI classroom. English Teaching Forum Online, 46(2). http://exchanges.state.gov/englishteaching/forum/archives.html (accessed 13/01/2010).

[25] Swain, M. (2000). The output hypothesis and beyond: Mediating acquisition through collaborative dialogue. In J. P. Lantolf (Ed.), Sociocultural theory and second language learning (pp. 97-114). Oxford: OUP.

[26] Ting, Y. L. T. (2009). Learning to hypothesize with confidence through Sudoku game play. English Teaching Forum Online, 48(1). http://exchanges.state.gov/englishteaching/forum/archives.html (accessed 13/01/2010).

[27] Tully, M. M. (2009). Mind mirror projects: A tool for integrating critical thinking into the English language classroom. English Teaching Forum Online, 47(1). http://exchanges.state.gov/englishteaching/forum/archives.html (accessed 13/01/2010).

[28] Tuksinvarajarn, A., \& Todd, R. W. (2009). The E-pet: Enhancing motivation in E-portfolios. English Teaching Forum Online, 48(2). http://exchanges.state.gov/englishteaching/forum/archives.html (accessed 13/01/2010).

[29] Van Lier, L. (2000). From input to affordance: Social-interactive learning from an ecological perspective. In J. P. Lantolf (Ed.), Sociocultural theory and second language learning (pp.245-260). Oxford: OUP.

[30] Young, R. F. (forthcoming). Interactional competence in language learning, teaching, and testing. In E. Hinkel (Ed.), Handbook of research in second language teaching and learning ( $2^{\text {nd }}$ ed.). NY: Routledge.

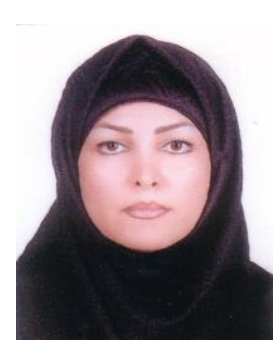

Minoo Alemi is a Ph.D. candidate of TEFL at Allameh Tabataba'i University. She is also a faculty member and vice-Dean of Education at Languages and Linguistics Department at Sharif University of Technology. She has taught English courses for over a decade at different universities in Tehran. Moreover, she has published many articles in international journals and more than ten English textbooks for GE and ESP courses.

Parisa Daftarifard is currently a PhD student at Azad University, Science and Research Branch, Tehran, Iran. She received her MA degree from Iran University of Science and Technology in 2002. Her primary research interests concerns EFL reading, testing, and second language acquisition. 